\title{
Medullary Regions Mediating Atonia
}

\author{
Y. Y. Lai and J. M. Siegel \\ Veterans Administration Medical Center, Sepulveda, California 91343, and Department of Psychiatry School of Medicine, \\ University of California, Los Angeles, California 90024
}

\begin{abstract}
Electrical stimulation studies have implicated the medial medulla in the inhibition of muscle tone. In the present report we present evidence for suppression of muscle tone by chemical activation of the medial medulla. We find 2 distinct zones within the classically defined medial medullary inhibitory area. A rostral region corresponding to the nucleus magnocellularis (NMC) is sensitive to glutamate. Atonia produced by activation of this region is mediated by non-NMDA receptors. A caudal region, corresponding to the nucleus paramedianus (NPM) is sensitive to ACh. Atonia produced by activation of this region is mediated by muscarinic receptors. Activation of these regions both in acute decerebrate and intact cats suppresses muscle tone. We find that the cholinoceptive dorsolateral pontine region, previously implicated in atonia control, can be activated by glutamatesensitive non-NMDA receptors. Microinjection of atropine into the NPM or of glutamylglycine into the NMC blocks atonia elicited by pontine carbachol injection. The medullary regions identified here are hypothesized to mediate the suppression of muscle tone that occurs in rapid eye movement sleep and in cataplexy and may have a role in postural control in waking.
\end{abstract}

Magoun (1944) and Magoun and Rhines (1946) first reported that electrical stimulation of the medial medulla produced a complete suppression of muscle tone. Neurons or pathways in this region are thought to mediate the muscle tone suppression that occurs during rapid eye movement (REM) sleep and during cataplectic episodes in narcoleptics (Morrison, 1983; Lai et al., 1987; Siegel et al., 1989). However, because electrical stimulation activates both fibers of passage and cell bodies, the location of the neuronal somas responsible for medullary inhibition and the transmitters to which they might respond have been unclear. A number of studies have shown that cholinergic stimulation of the dorsolateral pons elicits atonia (George et al., 1964; Baxter, 1969; Mitler and Dement, 1974; Baghdoyan et al., 1984; Katayama et al., 1984; Shiromani et al., 1986). However, repeated investigations have shown that cholinergic stimulation of the presumed rostral medullary inhibitory region does not produce atonia (Baghdoyan et al., 1984; Shiromani et al., 1986).

In the present study, we demonstrate that atonia can be generated by chemical stimulation of 2 distinct regions of the medial

Received Mar. 2, 1988; revised May 9, 1988; accepted May 10, 1988.

Supported by the Medical Research Service of the Veterans Administration, USPHS Grants NS 14610 and MH 43811, and the American Narcolepsy Association. We thank James Chang for excellent technical assistance.

Correspondence should be addressed to Y. Y. Lai, Neurobiology Res. 151A3, VAMC, Department of Psychiatry UCLA, Sepulveda, CA 91343.

Copyright $\odot 1988$ Society for Neuroscience $0270-6474 / 88 / 124790-07 \$ 02.00 / 0$ medulla, the nucleus magnocellularis (NMC) of the rostral medulla and the nucleus paramedianus (NPM) of the caudal medulla. Glutamatergic, but not cholinergic, stimulation of the NMC produces atonia. Cholinergic, but not glutamatergic, stimulation of the NPM produces atonia. These data reveal a previously unknown chemical and anatomical organization in the pontomedullary "inhibitory system." A brief report of these findings has appeared (Lai and Siegel, 1987).

\section{Materials and Methods}

Acute studies were performed on 30 unanesthetized cats decerebrated at the precollicular level under halothane anesthesia, as previously described (Lai et al., 1987). Chronic studies were performed on unanesthetized unrestrained cats. Details of the chronic cannula implant and injection procedures have been presented (Shiromani et al., 1986). The inhibitory areas in pontine and medial medullary reticular formation (PRF and MMRF) were identified by electrical stimulation $(500 \mathrm{msec}$ trains at $100 \mathrm{IIz}, 20-60 \mu \mathrm{A}, 0.2 \mathrm{msec}$ cathodal rectangular pulscs). When a point at which electrical stimulation produced bilateral suppression of muscle tone (with onset within $10 \mathrm{msec}$ in the splenius, occipitoscapularis, and biventer cervicis muscles) was identified, the stimulating electrode was removed and $0.5 \mu \mathrm{l}$ of the agonist test solution was injected. Microinjections were made through a 26-gauge Hamilton $1 \mu \mathrm{l}$ microsyringe over a period of $1 \mathrm{~min}$. In studies in which the action of antagonist (or control Ringer's) was examined, antagonist injections were performed $1 \mathrm{hr}$ after baseline agonist injections. Five minutes later the agonist was reapplied. Agonist was microinjected after $1 \mathrm{hr}$ to confirm the return of baseline response. Unilateral injections were performed in all mapping studies, while bilateral NMC and NPM injections were utilized to block atonia elicited by pontine carbachol injection. Target areas ranged from P3-P5, L0-L3 in PRF and P8-P15, L0-L2 in MMRF. At the end of the infusion studics, current was passed through a microelectrode to deposit iron at the most ventral point of injection. The animals were perfused with saline followed by $10 \%$ formalin solution. The brain stems were removed, stored in $30 \%$ sucrose-formalin solution, and then cut serially at $40 \mu \mathrm{m}$. Staining with Neutral red and counterstaining with ferrocyanide was used to localize the injection sites.

All chemicals were dissolved in Ringer's solution and adjusted to a $\mathrm{pH}$ of 7.4, at the concentrations of $0.05-0.4 \mathrm{M}$ of L-glutamic acid (glutamate), $0.2 \mathrm{M}$ of L-glutamic acid diethyl ester (GDEE), $10 \mathrm{~mm}$ of gamma-D-glutamyglycine (DGG), $50 \mathrm{mM}$ of DL-2-amino-5-phosphonovaleric acid (APV), 1.4-6.8 mM of $N$-methyl-D-aspartic acid (NMDA), 9.0 $\mu \mathrm{M}-0.9 \mathrm{mM}$ of kainic acid (KA), $0.2-5.0 \mathrm{~mm}$ of quisqualic acid (QA), $1.1 \mathrm{~m}$ of ACh, 44-100 mM of carbachol, and $7 \mathrm{~mm}$ of atropine.

\section{Results}

Microinjection of glutamate into the PRF and ventral rostromedial medullary reticular formation (rMMRF) produccd bilateral inhibition of muscle tone (Fig. 1, Table 1). Ringer's vehicle injection did not produce any effect on muscle tone. Microinjection of glutamate into caudal MMRF (cMMRF) did not produce atonia $\left(20 / 21\right.$ sites in 8 cats; $\left.p<0.001, \chi^{2}\right)$. The effective points in rMMRF were concentrated in the NMC (Fig. 2). Injections of glutamate at points in the dorsal rMMRF did not induce any change of muscle activity or increased muscle tone, even though electrical stimulation of these points produced 


\section{GLUTAMATE \\ $(0.2 \mathrm{M} / 0.5 \mu \mathrm{l})$}

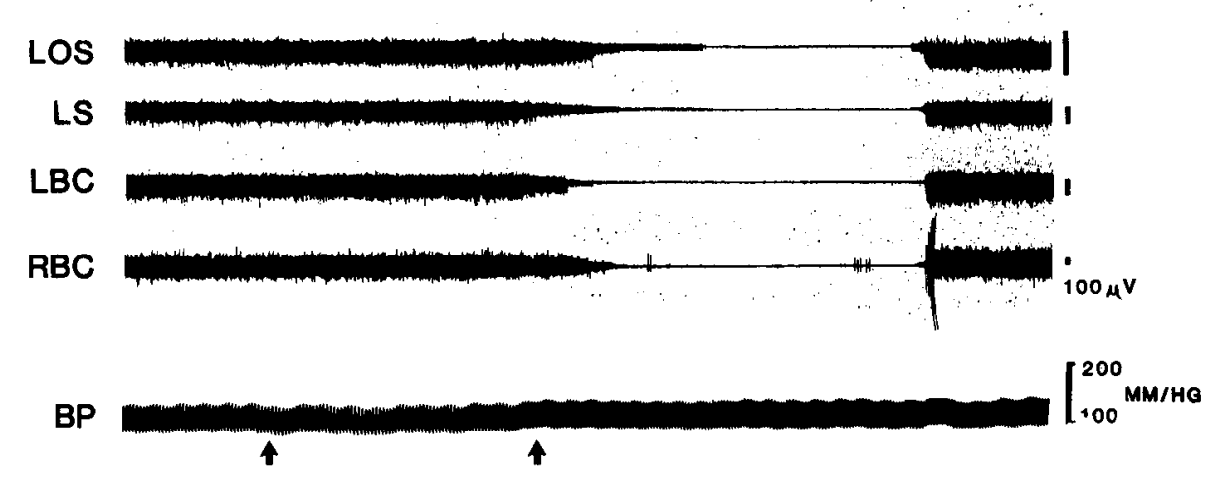

GLUTAMATE AFTER DGG

$(0.2 M / 0.5 \mu \mathrm{l}) \quad(1 \mu \mathrm{G} / 0.5 \mu \mathrm{I})$

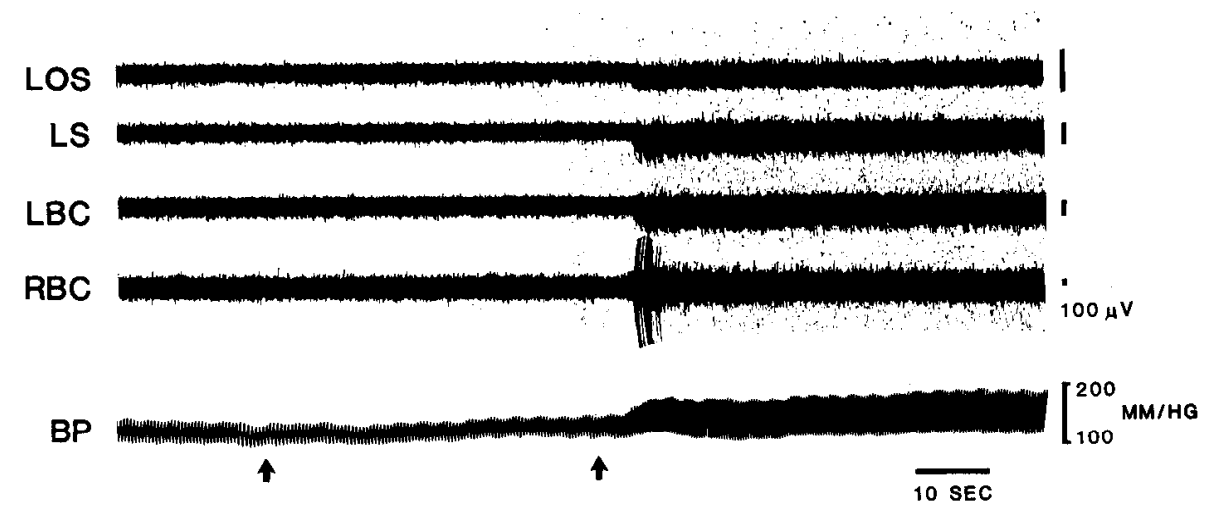

Figure 1. Effect of glutamate microinjection in nucleus magnocellularis $(N M C)$ on muscle tone in left occipitoscapularis $(L O S)$, left splenius $(L S)$, and left and right biventer cervicis $(L B C$, $R B C$ ). Glutamate injection after prior injection of DGG produces increased, rather than decreased, muscle tone. $B P$, blood pressure recorded from a catheter in the femoral artery. Arrows indicate onset and offset of microinjection. atonia. Similarly, glutamate injection in trapezoid body, pyramidal tract, and other areas in which electrical stimulation increased muscle tone had no effect or increased activity. The magnitude and duration of the inhibition produced by glutamate injection in the NMC was dose dependent (Fig. 3). At $0.05 \mathrm{M}$, glutamate injection produced only a small decrease in tone, with none of the 6 muscles recorded completely atonic. At $0.1 \mathrm{M}$, all 6 recorded muscles showed decreased tone, although none was completely atonic. At a $0.2 \mathrm{M}$ dose, 4 muscles were completely atonic, while at $0.4 \mathrm{M}$, all six muscles were completely atonic. The duration of inhibition below baseline values was also dose dependent (Fig. 3).

To identify receptors involved in the mediation of muscle inhibition, receptor antagonists were microinjected intracerebrally. DGG, which is a NMDA and KA receptor antagonist, blocked glutamate-induced muscle inhibition in the pons $(8 / 8$ sites in 7 cats) and in the NMC (11/11 sites in 8 cats; Fig. 1). GDEE, which is a NMDA and QA receptor antagonist (Davies and Watkins, 1981), blocked or attenuated the effect of glutamate on muscle activity in both PRF ( $8 / 8$ sites in 8 cats) and NMC (6/7 sites in 7 cats). However, APV, which is a highly specific NMDA receptor blocker (Jones et al., 1984) did not block the glutamate-induced atonia in the pons $(8 / 9$ sites in 5 cats) or in the NMC ( $4 / 4$ sites in 3 cats). The differences in antagonist effects were highly significant in both PRF and rMMRF $\left(p<0.001, \chi^{2}\right)$, indicating that glutamate-induced suppression of muscle tone in the PRF and NMC is mediated by non-NMDA receptors.

Agonist studies confirmed this conclusion. NMDA injected into either PRF ( 3 sites in 2 cats) or NMC ( 6 sites in 2 cats) produced excitatory or mixed effects on muscle activity. At doses below $2.7 \mathrm{mM}$, NMDA produced only excitation. At 6.8 mM, NMDA produced excitation followed by inhibition. In contrast, low doses of KA (9-90 $\mu \mathrm{M})$ did not produce any change in muscle activity, while higher doses $(0.15-0.2 \mathrm{mM})$ induced bilateral inhibition. This inhibition was not due to depolarization blockade, since doses up to $0.9 \mathrm{~mm}$ still produced inhibition, and repeated injections at the same site produced repeated

Table 1. I atency and duration $(+S D)$ of atonia elicited by microinjection (doses listed in Fig. 2)

\begin{tabular}{lllllr} 
Region & Injectate & $\begin{array}{l}\text { Latency } \\
(\mathrm{sec})\end{array}$ & $\begin{array}{l}\text { Duration } \\
(\mathrm{min})\end{array}$ & $\begin{array}{l}\text { Sites } \\
\text { respond- No. } \\
\text { ing/in- } \\
\text { jected }\end{array}$ & $\begin{array}{l}\text { of } \\
\text { cats }\end{array}$ \\
\hline PRF & Glutamate & $24.0 \pm 13.8$ & $12.9 \pm 11.1$ & $16 / 16$ & 12 \\
& ACh & $25.0 \pm 8.6$ & $7.7 \pm 1.7$ & $5 / 5$ & 5 \\
rMMRF & Glutamate & $18.1 \pm 13.6$ & $4.2 \pm 3.6$ & $20 / 29$ & 17 \\
cMMRF & ACh & $34.0 \pm 21.4$ & $4.1 \pm 4.8$ & $16 / 18$ & 9 \\
\hline
\end{tabular}

Latencies calculated from the start of each microinjection. 

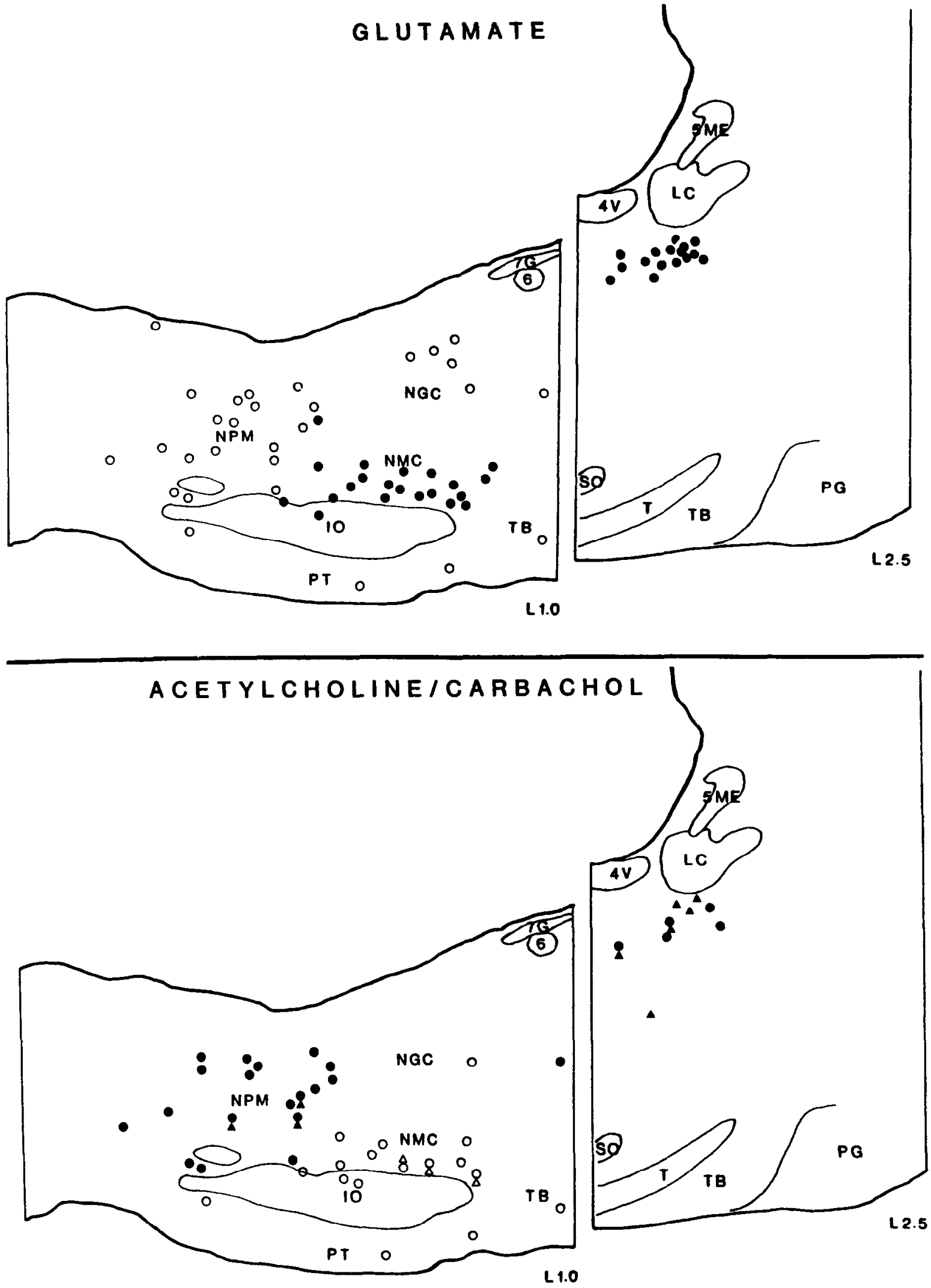

Figure 2. Schematic map of pontomedullary inhibitory areas. Electrical stimulation produced atonia at all the points mapped. All electrically defined inhibitory sites were microinjected with glutamate or cholinergic agonists. Filled symbols represent points at which microinjections decreased muscle tone (to less than $30 \%$ of baseline values or to complete atonia). Open circles indicate points at which injections increased or produced no change in baseline values. Glutamate $(0.2 \mathrm{M})$ injections are shown in the top panel, and ACh $(1.1 \mathrm{M})$ and carbachol $(0.01 \mathrm{M})$ injections in the bottom panel. In the bottom panel, circles and triangles represent $A C h$ and carbachol injections, respectively. $4 \mathrm{~V}$, fourth ventricle; $5 M E$, mescncephalic trigeminal tract; 6 , abducens nucleus; $7 G$, genu of the facial nerve; $I O$, inferior olivary nucleus; $L C$, locus coeruleus nucleus; $N G C$, nucleus gigantocellularis; $N M C$, nucleus magnocellularis; $N P M$, nucleus paramedianus; $P G$, pontine gray; $P T$, pyramid tract; $S O$, superior olivary nucleus; $T$, nucleus of the trapezoid body; $T B$, trapezoid body. 


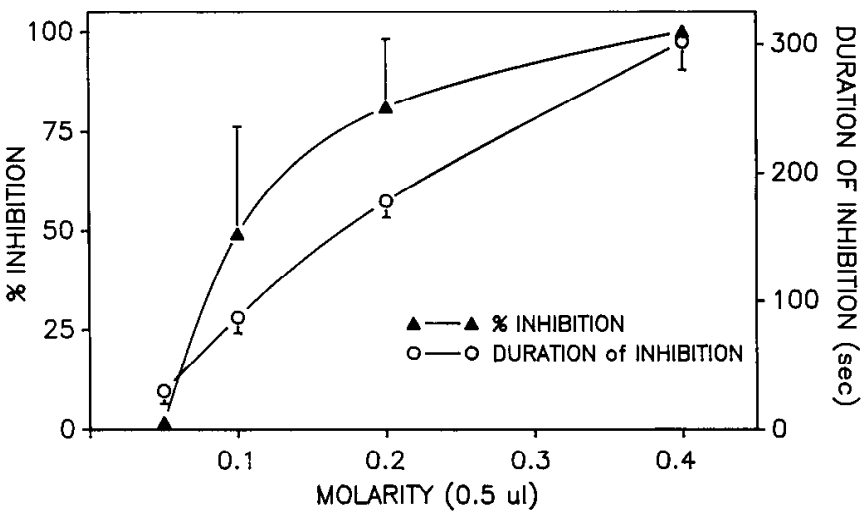

Figure 3. Effect of glutamate concentration on the magnitude and duration of motor inhibition. Magnitude was calculated with reference to integrated EMG amplitude in $3 \mathrm{~min}$ baseline period. Concentration of glutamate was varied from 0.05 to $0.4 \mathrm{M}$ in counterbalanced order. Curves are fit with cubic spline interpolations. Each point is based on the mean activity in the 6 recorded muscles (left and right occipitoscapularis, splenius, and biventer cervicis).

inhibition, indicating that the neuronal elements mediating the atonia response were not damaged by effective injections. Similar results were found after QA injection. The threshold for QA-evoked inhibition was $0.2 \mathrm{mM}$, comparable to that seen for KA.
Both ACh and its agonist, carbachol, were found to induce muscle atonia in PRF and cMMRF (Table 1) but not in rMMRF $\left(p<0.001, \chi^{2}\right)$. Microinjccted atropine blocked the effect of ACh on muscle activity at both sites (Fig. 4). Effective sites in the medulla corresponded to the NPM (Fig. 2). Carbachol microinjection into NPM ( $3 / 3$ in 3 cats) produced a longer latency (mean, $2.4 \pm 0.8 \mathrm{~min}$ ) suppression of muscle activity. Complete loss of muscle tone after carbachol lasted for more than $4 \mathrm{hr}$ and was followed by alternation of episodes of atonia and muscle activity for another $12 \mathrm{hr}$. In rMMRF, injection of ACh had no effect on muscle activity $\left(15 / 17\right.$ in 10 cats; $\left.p<0.001, \chi^{2}\right)$. However, carbachol injection induced muscle atonia after a very long latency ( $>20 \mathrm{~min}$ ). ACh is rapidly inactivated by hydrolysis, while carbachol is completely resistant to hydrolysis by both acetylcholinesterase and plasma pseudocholinesterase (Wurzel, 1959). Therefore, the presence of atonia at long latencies after infusion of carbachol into rMMRF is likely to be due to carbachol diffusion into PRF and/or NPM rather than a direct effect on the ncurons in the rMMRF.

We found that bilateral microinjection of $D G G$ into $N M C$ blocked pontine carbachol-induced atonia ( $3 / 3$ in 3 cats; Fig. 5). Bilateral atropine injection into NPM also blocked pontine carbachol-induced atonia $(2 / 2$ in 2 cats). However, vehicle (Ringer's) injection did not have any effect on muscle atonia resulting from pontine carbachol injection ( $4 / 4$ in 4 cats). This

A

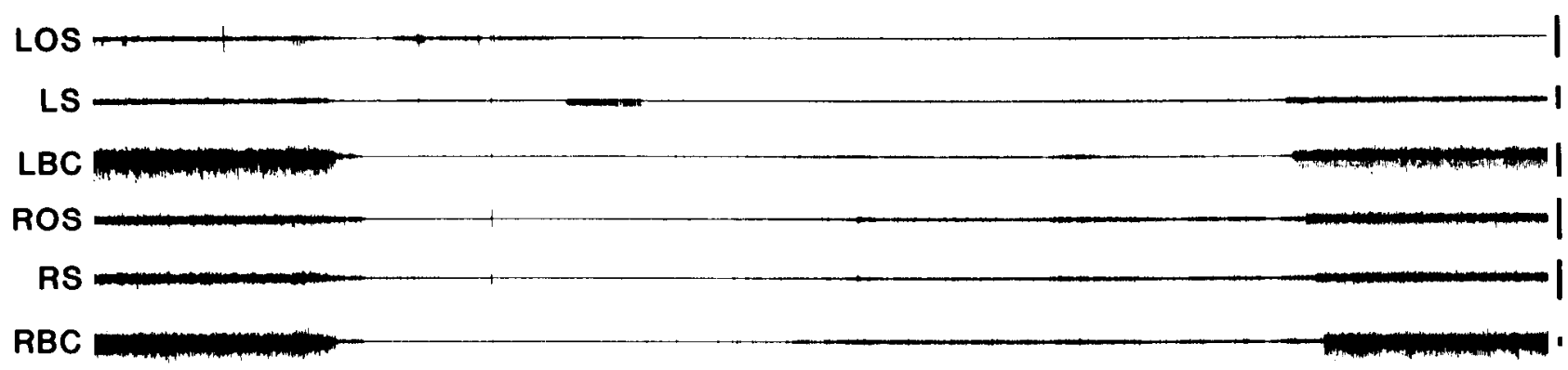

LTB
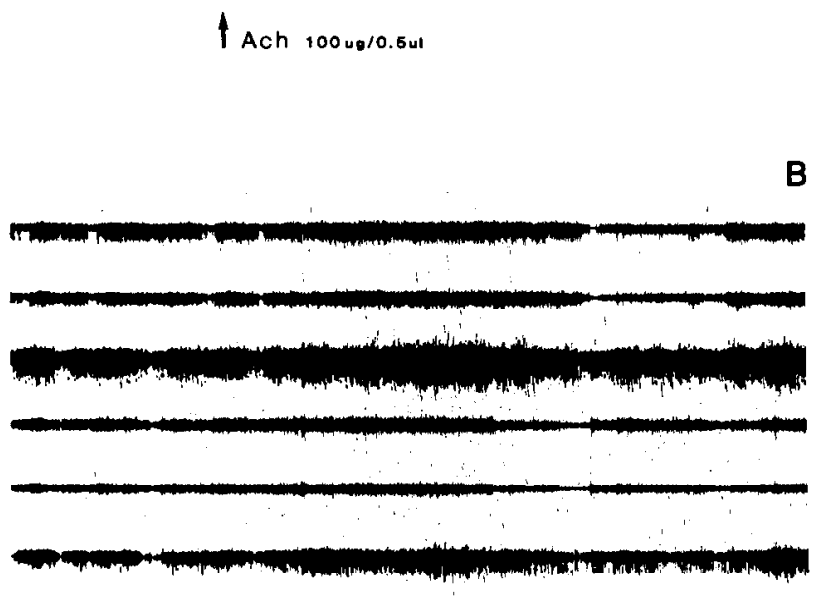

Atropine 1ug/0.5ul

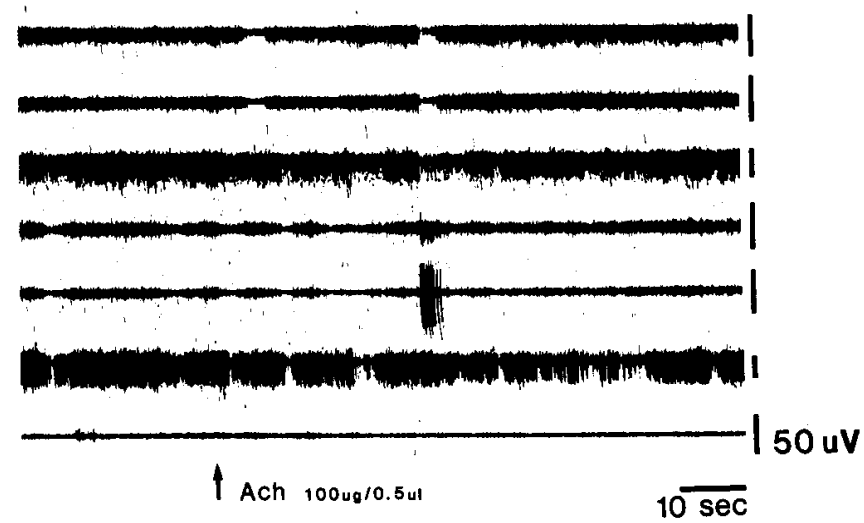

Figure 4. Effect on muscle activity of microinjection of ACh and the antimuscarinic, atropine, into caudal medial medullary reticular formation. $A$, ACh injection produced muscle atonia. $B$, Atropine injection at the same point followed after 5 min by ACh. Atropine blocked ACh-induced muscle atonia. $L O S, R O S$, left and right occipitoscapularis; $I S$, $R S$, left and right splenius; $L B C, R B C$, left and right biventer cervicis; $L T B$, left triceps brachii. 


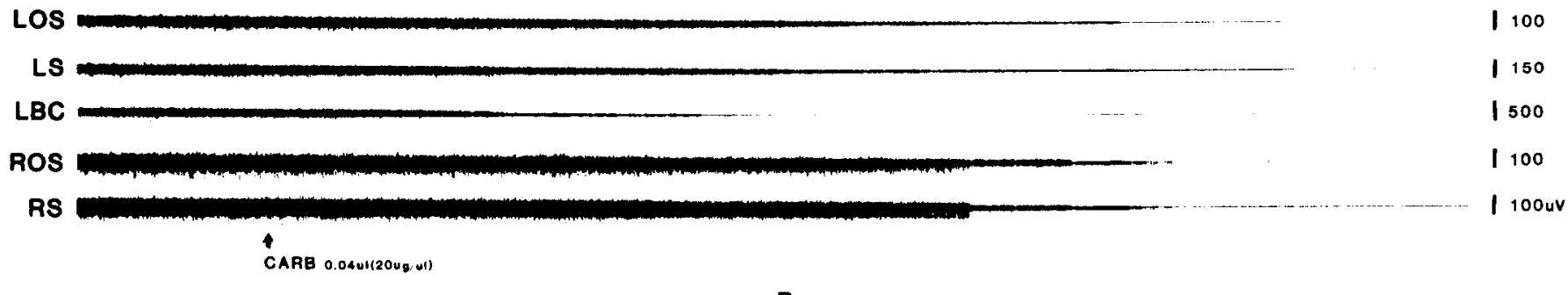

$\mathbf{B}$
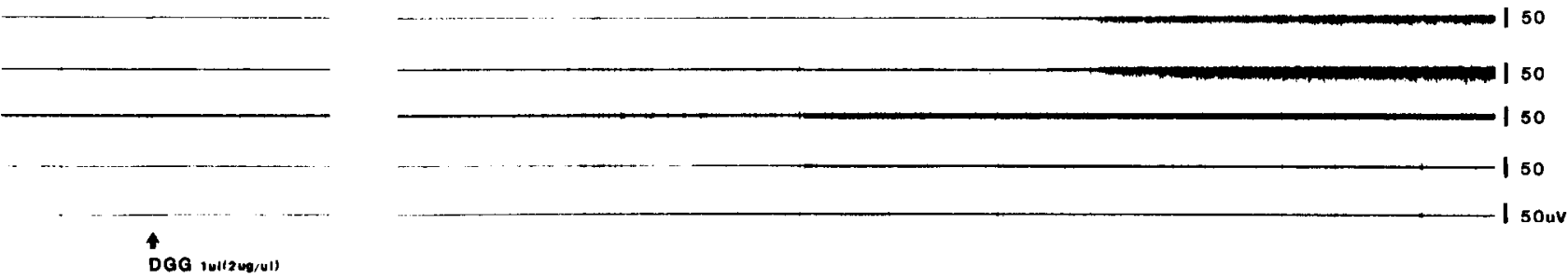

DQG ivilavg/ul

C

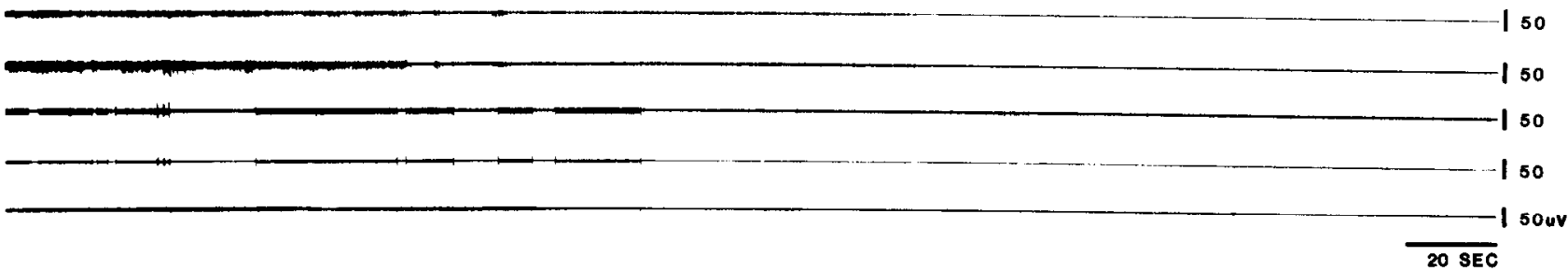

Figure 5. Effect of DGG on pontine carbachol-induced muscle atonia. $A$, Carbachol injection in dorsolateral pontine tegmentum produced muscle atonia. $B$, Two minutes after bilateral microinjection of DGG into the nucleus magnocellularis of the medulla, muscle tone was restored. $C$, Muscle atonia reappeared $29 \mathrm{~min}$ after DGG injection.

indicates that both NPM and NMC contribute to the mediation of pontine elicited carbachol atonia.

We injected $\mathrm{ACh}(1.1 \mathrm{M})$ and glutamate $(0.1 \mathrm{M})$ in 2 unanesthetized cats, aiming at the areas defined in our acute studies. We used chronically implanted 23-gauge guide cannulas to position 29-gauge injection cannulas, following the injection procedures described above. We found that glutamate injections in NMC and ACh injections in NPM reduced muscle tone in both chronic animals, as in the decerebrate (Fig. 6).

\section{Discussion}

The medullary inhibitory area defined by the present study is considerably smaller than the medullary inhibitory area indicated by electrical stimulation studies. Furthermore, it can be subdivided into 2 pharmacologically distinct zones: a glutamatesensitive zone in the $\mathrm{MMMRF}$ corresponding to the NMC and an ACh-sensitive zone in the cMMRF corresponding to the NPM. The rostral medullary region was sensitive to glutamate, but insensitive to $\mathrm{ACh}$, while the caudal medullary region was sensitive to $\mathrm{ACh}$, but insensitive to glutamate. The pontine atonia generating area, which corresponds to the dorsal portion of the nucleus pontis centralis oralis (Taber, 1961), and the peri-locus coeruleus $\alpha$ (Sakai, 1980), was sensitive to both glutamate and $\mathrm{ACh}$. Pontine and medullary glutamate-sensitive sites were found to utilize non-NMDA receptors.

Although electrical stimulation of the medulla generates atonia, the medullary region is not sufficient to generate atonic periods by itself. The chronic medullary animal never shows periods of atonia (Siegel et al., 1986b). In the otherwise intact animal, small lesions in the dorsolateral pons permanently block the atonia of REM sleep (Jouvet and Delorme, 1965; Henley and Morrison, 1974). Thus, activity in the pons is required for spontaneous atonia. We hypothesize that the pontine triggering of atonia is mediated by medullary mechanisms consisting of glutamate- and ACh-sensitive neurons localized in NMC and NPM, respectively. This hypothesis is supported by our finding that glutamate antagonists injected into the rostral medulla and atropine injected in the caudal medulla block atonia elicited from pontine carbachol injection. Since pontine injections of both $\mathrm{ACh}$ and glutamate trigger atonia, the pontine neurons triggering atonia are either responsive to both substances or consist of 2 distinct, but anatomically intermingled, groups of neurons, one group being responsive to glutamate and the other to $\mathrm{ACh}$. The dorsolateral pontine region is known to project to the NMC (Sakai, 1980). We hypothesize that this projection activates non-NMDA glutamate receptors. Our results suggest that the NPM is also a link in the atonia pathway. Since there are few cholinergic neurons in the NMC of the cat (Kimura et al., 1981; Jones and Yang, 1985; Reiner and Vincent, 1986; Jones and Beaudet, 1987), we hypothesize that the cholinoceptive NPM receives projections from the dorsolateral pontine cholinergic cell groups adjacent to the pontine cholinoceptive region or from lateral medullary cholinergic neurons (Jones and Beaudet, 1987). Both NMC and NPM have massive spinal projections (Torvik and Brodal, 1957; Tohyama et al., 1979; Hayes and Rustioni, 1981; Zemlan et al., 1984; Jones et al., 1986) and have been shown to produce IPSPs in cervical (Peterson et al., 1979) and lumbar (Jankowska et al., 1968) motoneurons. ACh 
WAKING

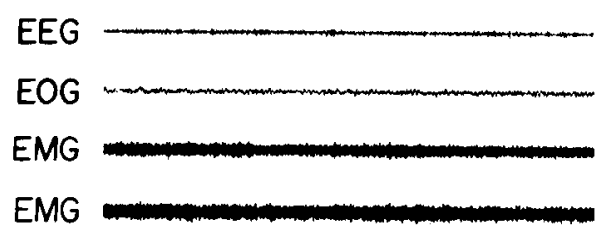

SLOW WAVE SLEEP

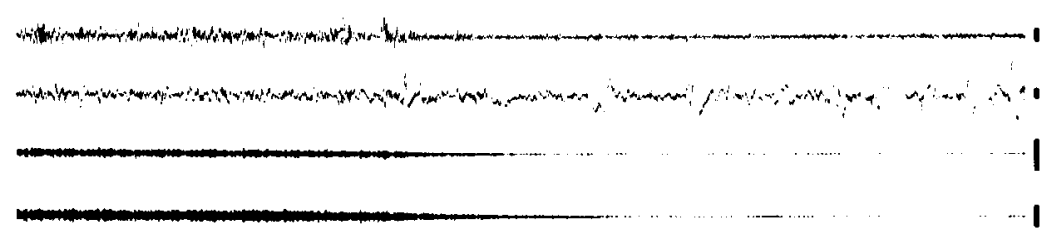

REM SLEEP

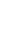

\section{ACH INJECTION}

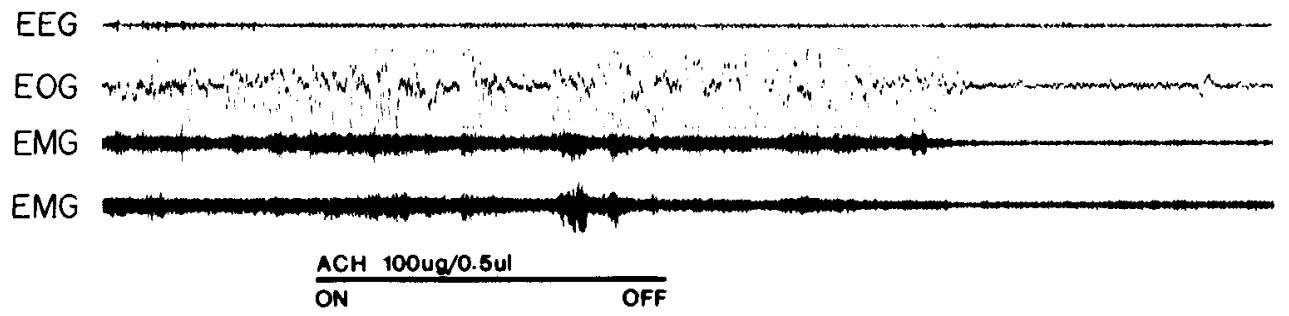

RECOVERY

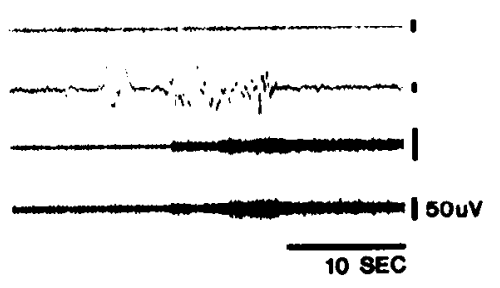

Figure 6. Effect of microinjection of ACh into the $\mathbf{n}$. paramedianus of the medial medulla in the intact, unanesthetized cat. During baseline periods EMG is present in quiet waking (sample shows lowest waking EMG level seen in $6 \mathrm{hr}$ baseline recording), is diminished in non-REM sleep, and is absent in REM sleep (ECG visible). Unilateral ACh microinjection reduces tone below the lowest waking and non-REM sleep levels, although not quite to the levels seen in REM sleep. EMG returns to baseline levels within 5-10 min. Effects were reproducible with repeated injections spaced $4 \mathrm{~d}$ apart.

and excitatory amino acids microinjected in the vicinity of the NMC, especially in the raphe magnus, have been shown to affect spinal inhibition related to nociception, but these effects have been reported to occur without alterations in muscle tone (Aimone and Gebhart, 1986; Brodie and Proudfit, 1986).

The pontine and rostral medullary regions, which can be chemically activatcd to producc atonia, contain subpopulations of neurons that are selectively active during the atonia of REM sleep and during waking postures associated with reduced muscle tone (Netick et al., 1977; Siegel et al., 1979; Kanamori et al., 1980; Chase et al., 1981). Narcoleptics periodically experience episodes of cataplexy, a sudden loss of muscle tone arising in waking without loss of consciousness. Recent work has shown that cells localized to the NMC are selectively active during these cataplectic attacks (Siegel et al., 1987). Narcoleptic animals have elevated levels of cholinergic receptors in the nucleus pontis centralis oralis (Boehme et al., 1984). Thus, activation of this pontomedullary circuit is likely to mediate the sudden loss of muscle tone in cataplexy, as well as the normal atonia of REM sleep.

The caudal medullary region, centered on NPM, has not been previously implicated in the control of atonia, although shortlatency IPSPs in neck motoneurons resulting from electrical stimulation of the NPM have been reported (Peterson et al., 1978). Neurons in the NPM have been shown to be activated by iontophoresis of ACh (Avanzino et al., 1966, 1975). This region receives input from baroreceptors and has been hypothesized to serve as a center for the integration of postural and blood pressure information (Homma et al., 1970; Miura and Reis, 1971; Doba and Reis, 1972; Elisevich et al., 1985, 1987). Cataplectic attacks are preceded by marked increases in heart rate and can be precipitated by blood pressure increases (Siegel et al., 1986a, 1989). The paramedian region may be responsible for these effects. Future studies should be directed at characterizing the interactions between NMC, NPM, and peri-locus coeruleus $\alpha$ in generating atonia during REM sleep and cataplexy and in their role in other diseases characterized by motor tone abnormalities.

\section{References}

Aimone, L. D., and G. F. Gebhart (1986) Stimulation-produced spinal inhibition from the midbrain in the rat is mediated by an excitatory amino acid neurotransmitter in the medial medulla. J. Neurosci. 6 : 1803-1813.

Avanzino, G. L., P. B. Bradley, and J. H. Wolstencroft (1966) Pharmacological properties of neurones of the paramedian reticular nucleus. Experientia 22: 410.

Avanzino, G. D., P. B. Bradley, and J. H. Wolstencroft (1975) Pharmacological and electrophysiological characteristics of neurones in the paramedian reticular nucleus. Arch. Ital. Biol. 113: 193-204.

Baghdoyan, H. A., M. L. Rodrigo-Angula, R. W. McCarley, and J. A. Hobson (1984) Site-specific enhancement and suppression of desynchronized sleep signs following cholinergic stimulation of three brainstem regions. Brain Res. 306: 39-52.

Baxter, B. L. (1969) Induction of both emotional behavior and a novel form of REM sleep by chemical stimulation applied to cat mesencephalon. Exp. Neurol. 23: 220-229.

Boehme, R. E., T. L. Baker, I. N. Mefford, J. D. Barchas, W. C. Dement, and R. D. Ciaranello (1984) Narcolepsy: Cholinergic receptor changes in an animal model. Life Sci. 34: 1825-1828.

Brodie, M. S., and H. K. Proudfit (1986) Antinociception induced by local injections of carbachol into the nucleus raphe magnus in rats: Alteration by intrathecal injection of monoaminergic antagonists. Brain Res. 371: 70-79.

Chase, M. H., S. Enomoto, T. Murakami, Y. Nakamura, and M. Taira (1981) Intracellular potential of medullary reticular neurons during sleep and wakefulness. Exp. Neurol. 71: 226-233.

Davies, J., and J. C. Watkins (1981) Differentiation of kainate and quisqualate receptors in the cat spinal cord by selective antagonism with $\gamma$-D (and L)-glutamylglycine. Brain Res. 206: 172-177.

Doba, N., and D. J. Reis (1972) Cerebellum: Role in reflex cardiovascular adjustment to posture. Brain Res. 39: 495-500.

Elisevich, K. V., A. W. Hrycyshyn, and B. A. Flumerfelt (1985) Cerebellar, medullary and spinal afferent connections of the paramedian reticular nucleus in the cat. Brain Res. 332: 267-282.

Elisevich, K., M. M. Caverson, B. A. Flumerfelt, A. W. Hrycyshyn, and J. Ciriello (1987) Collateral branching in axonal projections to spinal cord from paramedian reticular nucleus neurons. Brain Res. 408: 227232. 
George, R., W. L. Haslett, and D. J. Jenden (1964) A cholinergic mechanism in the brainstem reticular formation: Induction of paradoxical sleep. Int. J. Neuropharmacol. 3: 541-552.

Hayes, N. L., and A. Rustioni (1981) Descending projections from brainstem and sensorimotor cortex to spinal enlargements in the cat. Single and double retrograde tracer studies. Exp. Brain Res. 41: 89107.

Henley, K., and A. R. Morrison (1974) A re-evaluation of the effects of lesions of the pontine tegmentum and locus coeruleus on phenomcna of paradoxical sleep in the cat. Acta Neurobiol. Exp. 34: 215232.

Homma, S., M. Miura, and D. J. Reis (1970) Intracellular recording from paramedian reticular neurons monosynaptically excited by stimulation of the carotid sinus nerve. Brain Res. 18: 185-188.

Jankowska, E., S. Lund, A. Lundberg, and O. Pompeiano (1968) Inhibitory effects evoked through ventral reticulospinal pathways. Arch. Ital. Biol. 106: 124-140.

Jones, A. W., D. A. S. Smith, and J. C. Watkins (1984) Structureactivity relations of dipeptide antagonists of excitatory amino acids Neuroscience 13: 573-581.

Jones, B. E., and A. Beaudet (1987) Distribution of acetylcholine and catecholamine neurons in the cat brainstem: A choline acetyltransferase and tyrosine hydroxylase immunohistochemical. J. Comp. Neurol. 261: 15-32.

Jones, B. E., and T. Z. Yang (1985) The efferent projections from the reticular formation and the locus coeruleus studied by anterograde and retrograde axonal transport in the rat. J. Comp. Neurol. 242: 5692.

Jones, B. E., M. Pare, and A. Beaudet (1986) Retrograde labeling of neurons in the brain stem following injections of $[3 \mathrm{H}]$ choline into the rat spinal cord. Neuroscience 18: 901-916.

Jouvet, M., and F. Delorme (1965) Locus coeruleus et sommeil paradoxal. C. R. Soc. Biol. 159: 895-899.

Kanamori, N., K. Sakai, and M. Jouvet (1980) Neuronal activity specific to paradoxical sleep in the ventromedial medullary reticular formation of unrestrained cats. Brain Res. 189: 251-255.

Katayama, Y., D. S. DeWitt, D. P. Becker, and R. L. Hayes (1984) Behavioral evidence for cholinoceptive pontine inhibitory arca: Descending control of spinal motor output and sensory input. Brain Res. 296: 241-262

Kimura, H., P. L. McGeer, J. H. Peng, and E. G. McGeer (1981) The central cholinergic system studied by choline acetyltransferase immunohistochemistry in the cat. J. Comp. Neurol. 200: 151-201.

Lai, Y. Y., and J. M. Siegel (1987) Localization of neurons and transmitters involved in the ponto-medullary inhibitory system. Soc. Neurosci. Abstr. 13: 261.

Lai, Y. Y., J. M. Siegel, and W. J. Wilson (1987) Effect of blood pressure on changes in muscle tone produced by stimulation of the medial medulla. Am. J. Physiol. 252: H1249-H1257.

Magoun, H. W. (1944) Bulbar inhibition and facilitation of motor activity. Science 100: 549-550.

Magoun, H. W., and R. Rhincs (1946) An inhibitory mechanism in the bulbar reticular formation. J. Neurophysiol. 9: 165-171.

Mitler, M. M., and W. C. Dement (1974) Cataplectic-like behavior in cats after micro-injection of carbachol in the pontine reticular formation. Brain Res. 68: 335-343.

Miura, M., and D. J. Reis (1971) The paramedian reticular nucleus: A site of inhibitory interaction between projections from fastigial nucleus and carotid sinus nerve acting on blood pressure. J. Physiol. (Lond.) 216: 441-460.
Morrison, A. R. (1983) A window on the sleeping brain. Sci. Am. 248: 94-102.

Netick, A., J. Orem, and W. Dement (1977) Neuronal activity specific to REM sleep and its relationship to breathing. Brain Res. 120:197207.

Peterson, B. W., N. G. Pitts, K. Fukushima, and R. Mackel (1978) Reticulospinal excitation and inhibition of neck motoneurons. Exp. Brain Res. 32: 471-489.

Peterson, B. W., N. G. Pitts, and K. Fukushima (1979) Reticulospinal connections with limb and axial motoneurons. Exp. Brain Res. 36 . $1-20$.

Reiner, P. B., and S. R. Vincent (1986) The distribution of tyrosine hydroxylase, dopamine-beta-hydroxylase, and phenylethanolamine$\mathrm{N}$-methyl transferase immunoreactive neurons in the feline medulla oblongata. J. Comp. Neurol. 248: 418-531.

Sakai, K. (1980) Some anatomical and physiological properties of pontomesencephalic tegmental neurons with special reference to the PGO waves and postural atonia during paradoxical sleep in the cat. In The Reticular Formation Revisited, J. A. Hobson and M. A. Brazier, eds., pp. 427-447, Raven, New York.

Shiromani, P. J., J. M. Siegel, K. S. Tomaszewski, and D. J. McGinty (1986) Alterations in blood pressure and REM sleep after pontine carbachol microinfusion. Exp. Neurol. 91: 285-292.

Siegel, J. M., R. L. Wheeler, and D. J. McGinty (1979) Activity of medullary reticular formation neurons in the unrestrained cat during waking and sleep. Brain Res. 179: 49-60.

Siegel, J. M., H. Fahringer, K. S. Tomaszewski, K. Kaitan, T. Kilduff, and W. C. Dement (1986a) Heart rate and blood pressure changes associated with cataplexy in canine narcolepsy. Sleep 9: 216-221

Siegel, J. M., K. S. Tomaszewski, and R. Nienhuis (1986b) Behavioral states in the chronic medullary and mid-pontine cat. Electroencephalogr. Clin. Neurophysiol. 63: 274-288.

Siegel, J. M., R. Nienhuis, R. Paul, H. Fahringer, T. Kilduff, and W. C. Dement (1987) Unit activity during cataplexy: First recordings of single neuron activity in the narcoleptic animal. Soc. Neurosci. Abstr. 13: 261 .

Siegel, J. M., K. S. Tomaszewski, H. Fahringer, G. Cave, T. Kilduff, and W. C. Dement (1989) Heart rate and blood pressure changes during sleep-waking cycles and cataplexy in the narcoleptic dog. Am. J. Physiol. (in press).

Taber, E. (1961) The cytoarchitecture of the brain stem of the cat. I. Brain stem nuclei of cat. J. Comp. Neurol. 116: 27-70.

Tohyama, M., K. Sakai, D. Salvert, M. Touret, and M. Jouvet (1979) Spinal projections from the lower brain stem in the cat as demonstrated by the horseradish peroxidase technique. I. Origins of the reticulospinal tracts and their funicular trajectories. Brain Res. 173: 383-403.

Torvik, A., and A. Brodal (1957) The origin of reticulo-spinal fibers in the cat. Anat. Rec. 128: 113-137.

Wurzel, M. (1959) A suggested mechanism for the action of choline esters on animal organs, inferred from a study of the effect of cholinebeta-methylcholine-, and thiocholine-esters. Experientia 15: 430-433.

Zemlan, F. P., M. M. Behbehani, and R. M. Beckstead (1984) Ascending and descending projections from nucleus reticularis magnocellularis and nucleus reticularis gigantocellularis: An autoradiographic and horseradish peroxidase study in the rat. Brain Res. 292: 207-220. 